\title{
BARRIERS TO KM BETWEEN ORGANISATIONAL CULTURES IN THE FACE OF CONCURRENT ENTERPRISING: HOW TO OVERCOME THEM?
}

\author{
Patricia Wolf ${ }^{1}$, Michael Wunram ${ }^{2}$ \\ 'Fraunhofer IAO, Nobelstraße 12, 70569 Stuttgart, GERMANY, Patricia.Wolf@iao.fhg.de \\ ${ }^{2} B I B A-B r e m e n$ Institute of Industrial Technology and Applied Work Science at the University of \\ Bremen, Hochschulring 20, 28359 Bremen, GERMANY, wun@biba.uni-bremen.de
}

\begin{abstract}
There is evidence that the way Knowledge Management is practised is strongly dependent on the cultural context in which it is embedded. In Concurrent/Extended Enterprises different cultures, and therefore different ways of dealing with the resource 'knowledge', collide and a new meta-culture evolves along the course of the co-operation. If the co-operating cultures are too heterogeneous and the evolved meta-culture is not capable of handling the discrepancies of the colliding organisational cultures, the co-operation runs the risk of failing. Therefore, cultural barriers to Knowledge Management must be identified and overcome. In the face of increasing application of the methods and tools of virtual organisations in co-operations, which are typically the increase of $I C$-technologies, the consideration of the cultural dimension becomes even more important due to the limited communication richness these technologies provide in contrast to face-to-face meetings. The authors present a multi-layered framework for classifying cultural barriers in Concurrent Enterprises as a common type of virtual co-operations. Further, the authors look at the cultural barriers to be overcome before companies actually engage in co-operations. These barriers were identified by the means of semi-structured interviews. In addition first ideas for how to overcome them will be provided.
\end{abstract}

\section{INTRODUCTION}

When looking at an organisation through the lenses of the knowledge-based theory of the firm Knowledge Management (KM) can be considered as being its most important strategic instrument. KM guides and supports companies in realising a shift from traditional Fordist organisational cultures towards cultures capable to cope with actual demands of new organisational structures. As many companies increasingly pay attention to their intangible assets, this shift will in future gain even more importance specially for Concurrent Enterprises (CE). Thus, there is a need to develop adequate and feasible concepts for $\mathrm{KM}$ in organisations with a certain degree of virtualness. 
A virtual organisation (VO) in the literature is broadly defined as " $[\ldots]$ a set of flexible and short-term multi-partner relationships among independent economic agents spanning multiple time zones and wide geographical locations; and mediated by networked information and communication technologies." (Tetteh 1999, p. 985). However, it is possible to identify a continuum of virtual business formats ranging from companies with high virtualness (e.g. companies who are engaged in a predominantly information intensive value chain, have extensive linkages with its environment and operate within a network of diverse and dispersed partners) and very low virtualness (companies engaged in a predominantly physical value chain with a very small co-operative partner network and limited to a single geographical location). Within this continuum of virtualness the Concurrent Enterprise is located somewhere between the middle and the lower end: Although it is in most cases initially designed as a network of different partners working together to fulfil a certain task or project, the co-operation is mostly surpassing the lifecycle of a project allowing by this to build up much more stable organisational structures, communication patterns and personal relationships. The authors assume that the degree of virtualness of VOs has a heavy impact on the design of a KM system aiming to support knowledge generation, sharing and reuse as well as organisational learning within a VO. In this paper we are focussing on Concurrent Enterprises representing a common type of VOs.

As companies concentrate on core processes and therefore have to inevitably collaborate with external partners, companies will have to open up, and therefore run the risk of becoming vulnerable towards cross-company knowledge spill over. An efficient flow of information and knowledge is key to the efficiency of intra- and specially inter-organisational KM processes in Extended and Virtual Enterprises. At this point one can easily perceive one of the dilemmas collaborating companies run into: traditional company cultures usually aiming at protecting their knowledge from the 'outside world' to a maximum extent, nowadays impose high barriers to the necessary knowledge transfer across Concurrent Enterprises, thus endangering the efficiency and effectiveness of high potential partnerships.

As the authors assume, a change of an organisation's behaviour primarily depends on a change of the organisational culture. Unfortunately, changing an organisational culture and the mindsets of the members working in it are aspects most difficult to address.

What does it then mean for the implementation of a KM-system in a Concurrent Enterprise when looking at organisational cultures? A Concurrent Enterprise has therefore to focus on the integration and probably on the change of the often very heterogeneous cultures of all partnering organisations. As the management of knowledge varies depending on the cultural context within it is practiced, managing knowledge across organisational boundaries and cultures is often considered as a threat for the individual organisational culture:

- Trying to establish a cross-company knowledge sharing culture means for each individual partner of the Concurrent Enterprise to change the existing patterns of (in)formal communication or even making them obsolete.

- The aim to obtain explicit knowledge out of the implicit one in the heads of the members of an organisation means that the values of the organisational culture might be questioned. If these values are made explicit, the organisational culture and their values could possibly be refused or changed, thus representing a 
danger for each individual organisational culture and therefore to the whole Concurrent Enterprise.

A natural reaction of an organisational culture against changes is to simply establish conscious or even unconscious barriers. This paper has the objective to give an insight into often encountered cultural barriers to Knowledge Management in Concurrent Enterprises by making use of Luhmann's understanding of organisational culture, and to propose solutions for how to overcome them. The authors consider a Concurrent Enterprise as a social system with a culture of its own that can't seen as simply consisting of the sum of the cultures of its elements (e.g. partnering companies, departments, groups etc.). However, the elements of that system usually have their particular cultures, which have to interact, and which have their particular patterns, strategies etc. to manage their intangible assets. This in turn means that different barriers related to KM have to be attributed to different cultural layers of an Concurrent Enterprise. Figure 1 illustrates this context.

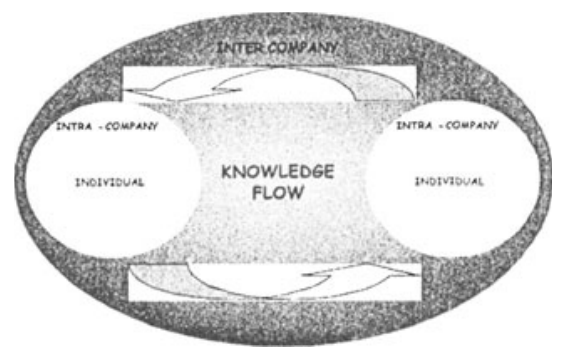

Figure 1: Different cultural layers in a Concurrent Enterprise

Long term aim of the authors is to develop a framework capable of classifying cultural barriers to $\mathrm{KM}$ on different cultural layers of a Concurrent Enterprise, that allows for the easy identification and allocation of concepts to overcome these barriers.

\section{EXISTING THEORIES AND WORK}

\subsection{Organisational culture}

Considering the assumption that each partner organisation of a Concurrent Enterprise is a social system as well as the Concurrent Enterprise itself, we have to scan the sociological theory of Social Systems in order to understand what is meant by organisational culture.

Luhmann refers to the definition of David Rodrigo who proposed to define organisational culture as "the complex of the not decidable premises of decisions" within an organisation. The most important insights this definition of organisational culture leads us to are:

- Organisational culture arises where problems appear which cannot be solved by hierarchical orders (e.g. the uniform presentation of an organisation to it's environment while there are different opinions/sentiments inside: Organisational culture regulates "how to make faces" without demanding from it's members to believe in the presented values). 
- An organisational culture gets it's particularity from the implicit or explicit reference to the history of the system. This history of decisions is very local, and that is the reason why there can be more than one consistent organisational culture in-side the same organisation.

- Organisational culture is produced by formal redundant communication like chats and informal conversations. The result of this communication is anonymously produced. The function of this kind of conversation is to express a spirit of belonging without discussing it directly as a theme in the communication in order to avoid occasions for accepting or refusing this spirit.

- The basic elements of organisational culture are values that are latently communicated within the organisation. The effort to address the values of an organisational culture to the organisation would make different intentions, interests and conflicts visible. This may lead to a change of the organisational culture. How this change will look like depends from the local receptions of how the organisation should be in the future. A cultural change can't be managed in terms of directing.

Building on Rodrigo's definition of 'organisational culture' the authors therefore extend this definition for a Concurrent Enterprise as follows:

"Organisational culture is the complex of the not decidable premises of decisions within an organisation that is build upon a network of organisations, each having its own culture."

The meta-culture emerging from the co-operation of at least two companies is not only a conglomerate of the cultures of the partnering organisations but a new culture, that influences the cultures of the co-operating companies and vice versa.

\subsection{Knowledge Management in Virtual Organisations}

Literature research on VOs points out that there is very limited literature on KM in organisations with a certain degree of virtualness. Furthermore, virtualness is hardly mentioned as an empirical example and learning theories are mostly focused on the discussion of KM within traditional organizations instead of taking in account the independent companies and its cultures involved in cooperating organisations.

BOSCH-SIJETSMA pointed out, that cooperation always implies knowledge transfer and learning from a partners procedures, skills, his way of working and routines. He proved in three case studies on inter-organisational projects that a high degree of virtualness (in his study indicated by high fluctuation of co-workers, a short lifecycle of the cooperation, geographical dispersion and ICT-dependence) makes it harder for the members of a VO to communicate informally. Knowledge transfer needs extensive personal contact, physical proximity and a common social culture are important for developing knowledge and for learning in an cooperation. BOSCH-SIJETSMA focused in his qualitative study on the knowledge transfer within the three different inter-organisational projects and developed general suggestions about how to overcome barriers to knowledge transfer like the exchange of researchers, face to face meetings and team-building events especially in the initial project phase and the explicit presentation of concepts for communication and information processing styles of members as well as the development and use of project-specific communication routines. 
SCHOLZ mentioned in his article on soft integration within VOs, that the integration of the different organisations or partners could not be understood as only the effort of putting together separated parts. The outcome of integration should be a unit which produces a total optimisation across the work value chain and a 'one face to the customer'. His solutions for soft integration are more general ones like constructing the VO without bureaucratic structures and administrative overhead, developing a mutual understanding of an almost symbiotic coexistence (co-destiny), sharing visions and goals and establishing a culture of virtuality by making common values among the cultures of the different partners explicit.

BARCIA et al described in their article a process of creating and disseminating knowledge in VOs. They identified potential barriers for learning and presented general strategies for overcoming such difficulties. Furthermore, they emphasised, that the degree of difficulty in creating and sharing knowledge in VOs is a reflection of the dominant organisational culture. For overcoming the barriers to KM in VOs it is proposed to bringing all people involved in a new project to the same organisational setting through intensive socialisation activities like training, story telling, common definition of project goals and roles, use of simulation techniques in order to provide a safe environment for experiments, promotion of ongoing discussions through the set up of Internet Newsgroups, rotation of experts, avoiding bureaucratic proceedings, stimulating dialogue between co-workers as well as 'think aloud' processes in order to undercover and formalise patterns of problem solutions. All three authors pointed out the importance of knowledge sharing and a trustful culture within VOs and developed potential solutions for how to overcome barriers to $\mathrm{KM}$ in this special organisational setting. Although, the last two mentioned developed this insight form a more general and abstract point of view. Only BOSCH-SIJTSMA proved the empirical evidence of his research results by three case studies, but with his concentration on knowledge transfer he has chosen a very limited focus on the overall theme. Thought the importance of organisational culture and its special influence on KM in VOs has been pointed out in all three articles, none of the authors draw the conclusions from this insight and researched the real needs and requirements to KM in VOs with different degrees of virtualness. This paper does not intend to close this entire gap. It rather tries to provide empirical evidence on what cultural barriers KM is facing within Concurrent Enterprises at the individual, intra-company and inter-company layer and to develop first solutions about how to overcome them.

\section{RESEARCH APPROACH}

What is the nature of barriers to Knowledge Management in Concurrent Enterprises resulting from heterogeneous organisational cultures? Within the a study performed during the IST Project CORMA No 1999-12685 the identification of barriers to Knowledge Management within and between organisations was one of the major objectives. The project's approach was to analyse organisational, technical and human barriers which hinder employees to identify, acquire, structure, generate, store, distribute and assess knowledge. This research has focused on organisations that had almost the same degree of virtualness, on Concurrent Enterprises. 
The outcome of that study were about 70 barriers to KM related to human, technological and organisational aspects in the product development process of an extended enterprise. The data was elevated through semi-structured interviews held within the co-operating companies. In addition to the interviews, and in order to not lose focus, barriers encountered at industrial companies outside the CORMA consortium were also assessed.

\section{FINDINGS}

The CORMA study provided the empirical background for the identification of cultural barriers to Knowledge Management on the three layers of the here presented framework. With a reference to the Knowledge Management literature, case studies and the theoretical assumptions of the theory of social systems barriers resulting from heterogeneous organisational cultures were analysed. Table 1 summarises the three most important barriers.

Table 1 - Cultural barriers to KM

\begin{tabular}{|l|l|l|}
\hline Barrier & $\begin{array}{l}\text { Cultural } \\
\text { layer }\end{array}$ & Description \\
\hline exploitation & Individual & $\begin{array}{l}\text { Individuals are in fear that if they share their } \\
\text { knowledge they won't get anything in return. }\end{array}$ \\
\cline { 2 - 4 } & $\begin{array}{l}\text { Intra- } \\
\text { company }\end{array}$ & $\begin{array}{l}\text { Project teams sharing knowledge with } \\
\text { competing project teams fear the lack of } \\
\text { acknowledgement for their results, thus } \\
\text { running the risk of losing advantages over } \\
\text { competing projects. }\end{array}$ \\
\hline $\begin{array}{l}\text { Refusal of } \\
\text { ICT } \\
\text { infrastructur }\end{array}$ & $\begin{array}{l}\text { Inter- } \\
\text { company }\end{array}$ & $\begin{array}{l}\text { Companies sharing knowledge with other } \\
\text { companies fear being exploited by co- } \\
\text { operating companies, and therefore lose } \\
\text { ground in competition. }\end{array}$ \\
\cline { 2 - 4 } & $\begin{array}{l}\text { Individuals are not accustomed to the use of } \\
\text { ICT tools and feel that face to face contact is } \\
\text { much more effective. In face to face } \\
\text { conversations exchanged information is much } \\
\text { more trusted than with ICT tools sent } \\
\text { information (written character is seen as more } \\
\text { official). }\end{array}$ \\
\cline { 2 - 4 } & $\begin{array}{l}\text { Intra- } \\
\text { company }\end{array}$ & $\begin{array}{l}\text { ICT tools are characterised as unreliable. The } \\
\text { usability of the Internet seems not to } \\
\text { correspond ideally with search for required } \\
\text { information within the daily work of users. }\end{array}$ \\
\cline { 2 - 4 } & $\begin{array}{l}\text { Inter- } \\
\text { company } \\
\text { company networks because of the lack of a } \\
\text { common ICT strategy. It is difficult to } \\
\text { convince companies to change their ICT } \\
\text { systems because this implies a cultural change } \\
\text { of ICT use and communication patterns. }\end{array}$ \\
\hline
\end{tabular}




\begin{tabular}{|c|c|c|}
\hline \multirow[t]{3}{*}{$\begin{array}{l}\text { International } \\
\text { differences }\end{array}$} & Individual & $\begin{array}{l}\text { Language barriers are considered to lead to } \\
\text { misunderstanding and unproductive } \\
\text { discussions. Individuals tend to produce } \\
\text { stereotypes about the work styles within other } \\
\text { countries and to characterise them as strange. } \\
\text { Time differences limit the availability of } \\
\text { partners for-even informal - communication. }\end{array}$ \\
\hline & $\begin{array}{l}\text { Intra- } \\
\text { company }\end{array}$ & $\begin{array}{l}\text { Companies in co-operations fell themselves in } \\
\text { danger of losing company focus because of a } \\
\text { to close collaboration with partners. They tend } \\
\text { to see the risk of losing competitive awareness } \\
\text { by no longer serving their home market. }\end{array}$ \\
\hline & $\begin{array}{l}\text { Inter- } \\
\text { company }\end{array}$ & $\begin{array}{l}\text { Limited time frames for collaboration due to } \\
\text { time differences and different work styles are } \\
\text { understood as inhibitors for effective co- } \\
\text { operation. Inter-company co-operations feel } \\
\text { that there is only a reduced space for creative } \\
\text { thinking. }\end{array}$ \\
\hline
\end{tabular}

As general pragmatic solutions and advices for Concurrent Enterprises how to overcome this barriers on the different cultural layers we developed the following first solutions:

1. To overcome the fear of exploitation, collaborating organisations should develop a very clear work plan and define roles and responsibilities. In terms of $\mathrm{KM}$ and culture that means to allow the people at least in the kick of phase of a collaboration project to meet phase to phase and to define their own CE culture. People should be supported to define visions and missions for their collaboration that are different from the ones the involved organisations have and to allocate within some kind of collaboration frame resources, roles and responsibilities according to their needs. Exchange of experts, training, story telling and other socialisation activities have to be fostered as well. The people involved in CEs should explicitly work on communication and working routines.

2. The ICT barrier can only be overcome when the co-operating organisations are ready to use the same specifications of ICT tools and systems. The best might be to set up for the $\mathrm{CE}$ a special collaboration system that is compatible with the ICT systems of all partners. Furthermore, for the usage of this tool intensive training activities are required. The implementation of newsgroups and discussion forum might provide an immaterial incentive to use this system because these tools are fostering community building and create a common spirit of belonging. This would help to overcome also the other two cultural barriers to knowledge exchange.

3. In order to overcome barriers arising form international differences, the KM methods above mentioned are highly recommended. Additionally, explicit cultural training as a part of the socialisation activities should be fostered. People should be aware that there are cultural differences, and they should together develop communication mechanisms for how to overcome them. 


\section{CONCLUSIONS}

The way $\mathrm{KM}$ is practised strongly depends on the cultural context in which it is placed. As organisational knowledge is bound to individuals because the organisation is lacking the capability of observing, sharing knowledge basically depends at least on three aspects: the decision to share and the communication behaviour, through which it is shared and the communication structure and patterns provided by the Concurrent Enterprise. Utmost attention has to be paid to both aspects within an organisational culture, and their compatibility to decision and communication structures of other organisational cultures in a Concurrent Enterprise. Still much research has to be done in order to understand better the relationships between different organisational cultures and Knowledge Management practised within and between them.

According to virtual organisations, one further research question will be the evaluation of which different kinds of cultural barriers $\mathrm{KM}$ is facing in VOs with varying degrees of virtuality and how these barriers might be overcome.

\section{REFERENCES}

1. Barson, R.J.; Foster, G.A.; Struck, T.; Ratchev, S.; Pawar, K.S.; Weber, F.; Wunram, M., (2000) Inter and Intra-Organisational Barriers to Sharing Knowledge in the Extended Supply-Chain, presented at EEMSEC 2000, Madrid 18th-20th October 2000

2. Barcia, R.M., Pacheco, C.S., Steil, A.V. (2002), An Approach to Learning in Virtual Organisations, available at http://www.virtual-organization.net

3. Bosch-Sijtsema, P.M. (2002), Knowledge Management in Virtual Organisations: Interorganisational and interproject knowledge transfer, presented at the Organizational Knowledge, Learning and Capabilities Conference 2002

4. Brandt, D.; Hartmann, E. (1999), Editorial: Research Topics and Strategies in Sociotechnical Systems, Human Factors and Ergonomics in Manufacturing 9(3) 241-243.

5. Doz, Y (1988), Technology partnerships between larger and smaller firms: some critical issues. In: F.J. Contractor, and P. Lorange (Eds.), Co-operative Strategies in International Business: Joint Ventures and Technology Partnerships. Lexington Books, Lexington, MA

6. Lakemond, N. (1999), Supplier Co-ordination in Product Development Projects: The Case of Tetra Brik. Linkoping Studies in Science and Technology Thesis No. 767.

7. Lank, E. (1997), Building structural capital: a new key to generating business value, Journal of Knowledge and Process Management 1(2) 73-79

8. Lucas, E. (2000), Created a give and take culture, Professional Manager 9(3), 11-13

9. Luhmann (2000), Organisation and decision, Wiesbaden

10. Nonaka, I. (1991), The Knowledge Creating Company, Harvard Business Review Novem-ber/December 96-104

11. Patzelt, W.J. (1986), Sozialwissenschaftliche Forschungslogik: Einführung. (in German) R. Oldenbourg Verlag. 2. Auflage. München, Wien 1987. R. Oldenburg Verlag. München, Wien, p. 44-46

12. Scholz, C. (1998), Towards the Virtual Corporation: A Complex Move Along Three Axes, Paper Nr. 62 of the Department of Management, Chair of Organizational Behavior and Human Resource Management at the University of Saarland, available at http://www.orga.uni-sb.de

13. Tetteh, E. (1999), From Business Networks to Virtual Organisation: A Strategic Approach to Business Environment Transformation in Online Small and Medium-sized Enterprises, Proc. $10^{\text {th }}$ Australasian Conference on Information Systems, 980-992 